\title{
Comparison Between Mordant and Alkaline Dyeing of Wool Fiber with Dyes from Rubia tinctorum Plant
}

\author{
Younes Chemchame*, Mohamed El Mouden, Anass Mansar \\ Department of Traditional Weaving, Academy of Traditional Arts, Foundation of Hassan II Mosque, Casablanca, Morocco \\ Email address: \\ ychem2@gmail.com (Y. Chemchame), emouddenmohamed@gmail.com (M. El Mouden), anass.mansar@gmail.com (A. Mansar) \\ ${ }^{*}$ Corresponding author
}

To cite this article:

Younes Chemchame, Mohamed El Mouden, Anass Mansar. Comparison Between Mordant and Alkaline Dyeing of Wool Fiber with Dyes from Rubia tinctorum Plant. American Journal of Physical Chemistry. Vol. 6, No. 1, 2017, pp. 1-5. doi: 10.11648/j.ajpc.20170601.11

Received: February 8, 2017; Accepted: February 20, 2017; Published: March 2, 2017

\begin{abstract}
We report comparative studies between mordant (with alum or tannin) and alkaline dyeing of wool fiber with dyes from the Rubia tinctorum plant. Mordant dyeing was achieved by using boiling extract of $R$. tinctorum, and alkaline dyeing was achieved at $\mathrm{pH} 10$ with alizarin extract of $R$. tinctorum. The alkaline process was used with and without Argan's pulp as a reducer. The fixation rate was higher in the alkaline dyeing process when a reducer was used, and the washing fastness was higher in the alkaline dyeing process with acidification post treatment. In mordant dyeing, tannin provide a greater fixation rate than alum.
\end{abstract}

Keywords: Wool, Alizarin, Mordant Dyeing, Alkaline Dyeing, Alum, Tannin, Rubia tinctorum

\section{Introduction}

The classical dyeing of wool fiber by using the Rubia tinctorum plant is based on the mordant process, and uses alum (aluminum and potassium bisulfate) as the mineral agent, or organic agent as the tannin (polyphenol, based on gallic or ellagic acids). Because wool fiber has no real substantivity towards colored pigment, the mordant acts as a mediator between the dye and the fiber. Therefore, it contributes to dye fixation on the fiber [1-3].

Dyeing recipes that use Rubia root particles can be divided into two main classes according to the origin of the material to be dyed, the number of process steps required and the necessary chemicals. The alizarin red procedure, which makes use of $R$. tinctorum root particles is used to dye animal-derived fibers such as wool, and the Turkish red procedure is used to dye plant-derived fibers such as cotton. The main steps in the alizarin red procedure are pre-treatment (washing to remove grease and mineral impurities), mordanting, dyeing and washing [4]. When using a tannin, mordanting can be achieved at the same time in the dyeing phase.

De Santis and Moresi report that dyed wool and cotton fibers with ethanolic or methanolic extract of alizarin from $R$. tinctorum had a lighter color and were more shaded than those dyed with Rubia root particles. However, the manual washing fastness at $40^{\circ} \mathrm{C}$ and acid or basic perspiration tests were found to be sufficiently high [5].

We used enzymatic hydrolysis (endogenous conversion) to convert glucosidic anthraquinones, and in particular, ruberythric acid, to alizarin [6-8] (see Section 2.4.2.). Alizarin dye extracts were used in the alkaline dyeing process.

The aim of this work was to compare the exhaustion and fixation dye rate of two wool fiber dyeing processes, namely, the mordant dyeing process using boiling extract from $R$. tinctorum plant and the alkaline dyeing process using alizarin dye that is extracted by enzymatic hydrolysis and the alkaline effect. The dyeing was used to improve the fastness of the dyed fiber and to achieve an increased pure coloration with alizarin dye instead of using different dyes extracted from $R$. tinctorum. We have tested and compared the washing fastness of both dyeing procedures (mordant and alkaline processes) with alkaline dyeing using Argan's pulp as a reducer (in the vat system). 


\section{Experimental}

\subsection{Material}

\subsubsection{Wool Fiber Features}

Wool fiber was from the Boujaâd city region in Morocco. White fleece was compacted and homogenized into a medium weight fleece $1.5-3 \mathrm{~kg}$ and the fineness of the fiber was 50-60 using the Bradford scale [9].

\subsubsection{Natural Dye}

Dye was extracted from the $R$. tinctorum plant, which grows in south-east Morocco [10]. The extraction method was based on enzymatic hydrolysis (endogenous conversion) of the dried and powdered root of the plant.

\subsubsection{Alum}

Crystal-shaped alum was from the herbalist shop.

\subsubsection{Tannin}

Tannin was from sumac trees (Rhus pentaphylla), which grow in several regions in Morocco [10]. The tannin is contained in the roots and the heartwood of the tree, and was extracted from boiling powdered and dried leaves.

\subsubsection{Chemicals}

Alkali reagents, sodium hydroxide $(\mathrm{NaOH})$ and sodium carbonate $\left(\mathrm{Na}_{2} \mathrm{CO}_{3}\right)$, and the acidic reagent, acetic acid $\left(\mathrm{CH}_{3} \mathrm{COOH}\right)$, were of analytical grade and were from Lobachemie Company (Mumbai, India), and VWR Prolabo Chemicals Company (Fontenay-Sous Bois, France), respectively. A Marseille soap type was prepared from vegetable oil, and was from a mini supermarket. Sodium chloride $(\mathrm{NaCl})$ was of technical grade and was from a mini supermarket.

\subsubsection{Argan's Pulp}

The reducing agent, Argan's pulp, was collected from around the Argan tree from the Essaouira city region of South Morocco. This natural product was composed of $20 \%$ reducer sugar, $13 \%$ cellulose, $6 \%$ protein, $2 \%$ fat and $4 \%$ latex (comprised of $86 \%$ of cis-polyisoprene: rubber) [09, 11, 12].

\subsubsection{Spectrophotometer}

An ultraviolet-visible (UV-vis) spectrophotometer (Thermo, Helios Epsilon) was used at 325-1100 nm with a spectral bandwidth of $1 \mathrm{~nm}$.

\subsection{8. $\mathrm{pH}$ Meter}

A Henne AD1000 pH meter was used. This multimeter can measure $\mathrm{pH}$, redox (oxidation-reduction) potential and temperature.

\subsubsection{Bath}

A $250-\mathrm{mL}$ flask was used. Heating was by a thermostat hotplate (Scilogex MS-H280-Pro).

\subsubsection{Filter}

Two types of filters were used in this study, namely, a metallic sieve (1-5-mm diameter) and a Büchner funnel with a conical flask.

\subsection{Dyeing Process}

\subsubsection{Preparation of Dyed Baths (Dye Bath 1, 2 and 3)}

$R$. tinctorum plant $(5 \mathrm{~g})$ was added to $500 \mathrm{~mL}$ distilled water and boiled for $30 \mathrm{~min}$. Three fractions of $100 \mathrm{~mL}$ were extracted. The $\mathrm{pH}$ of these fractions was $\sim 6$. The samples were filtered through a metallic sieve and were designated dye baths 1, 2 and 3 .

\subsubsection{Preparation of Alkaline Dye Bath (Dye Bath 4)}

A 2.5-g sample of the plant was stirred in $100 \mathrm{~mL}$ of water at $45^{\circ} \mathrm{C}$. After $1 \mathrm{~h}$, a solution of $0.1 \mathrm{~g} / 1 \mathrm{NaOH}$ was added to the plant solution. The solution $\mathrm{pH}$ was adjusted to 12.6 which gave a color change from yellow to purple. Water was added to make the solution up to $500 \mathrm{~mL}$, and the solution was stirred for $30 \mathrm{~min}$ at room temperature. One fraction of $100 \mathrm{~mL}$ was extracted and its $\mathrm{pH}$ was adjusted to 10 using $\mathrm{CH}_{3} \mathrm{COOH}$. The fraction was filtered using a Büchner funnel and designated dye bath 4 .

\subsubsection{Preparation of Reducer (Dye Bath 5)}

Argan's pulp ( $6 \mathrm{~g}$ ) was added to $500 \mathrm{~mL}$ of distilled water and heated at $95^{\circ} \mathrm{C}$ for $30 \mathrm{~min}$. The extract was filtered using a metallic sieve.

\subsubsection{Dyeing Conditions \\ i. Bath conditions}

The dyeing conditions for dye bath 1 (without mordant) were $100 \mathrm{~mL}$ of dye (extract prepared from $5 \mathrm{~g} \mathrm{R}$. tinctorum in $500 \mathrm{~mL}$ water) at $60^{\circ} \mathrm{C}$ for $30 \mathrm{~min}$ and with a liquor ratio of $1 / 100$.

The dyeing conditions for dye bath 2 (using tanning mordant) were $100 \mathrm{~mL}$ of dye (extract prepared from $5 \mathrm{~g} R$. tinctorum in $500 \mathrm{~mL}$ water), $10 \%$ tannin of sumac (own weight fiber: owf) and $5 \% \mathrm{CH}_{3} \mathrm{COOH}$ (owf) at $60^{\circ} \mathrm{C}$ for 30 min and with a liquor ratio of $1 / 100$.

The mordant treatment conditions for dye bath 3 (using alum mordant) were $10 \%$ alum (owf) at $95^{\circ} \mathrm{C}$ for $30 \mathrm{~min}$, with a liquor ratio of $1 / 100$ and a cold rinse. The dyeing conditions for dye bath 3 were $100 \mathrm{~mL}$ dye (extract prepared from $5 \mathrm{~g} \mathrm{R}$. tinctorum in $500 \mathrm{~mL}$ water) at $60^{\circ} \mathrm{C}$ for $30 \mathrm{~min}$ and with a liquor ratio of $1 / 100$.

The dyeing conditions for dye bath 4 were $100 \mathrm{~mL}$ dye (extract prepared from $2.5 \mathrm{~g} \mathrm{R}$. tinctorum in $500 \mathrm{~mL}$ water with $\mathrm{NaOH}$ ), $\mathrm{NaOH}$ and $\mathrm{CH}_{3} \mathrm{COOH}$ at $\mathrm{pH} 10$ at $60^{\circ} \mathrm{C}$ for 30 min and with a liquor ratio of $1 / 100$.

The dyeing conditions for dye bath 5 were $100 \mathrm{~mL}$ dye, using $10 \mathrm{~mL}$ Argan's pulp extract containing $6 \mathrm{~g}$ Argan's pulp in $500 \mathrm{~mL}$ water as a reducer, $0.1 \mathrm{~g} / \mathrm{L} \mathrm{Na}_{2} \mathrm{CO}_{3}(\mathrm{pH}=8)$, $5 \mathrm{~g} / \mathrm{L}$ sodium chlorate at $45^{\circ} \mathrm{C}$ for $30 \mathrm{~min}$ and with a liquor ratio of $1 / 100$.

The five samples of wool yarn $(1 \mathrm{~g})$ to be dyed in the five dye baths were soaked and wrung before being placed in the dyeing baths. At the end of the dyeing process, the five samples were wrung before being placed in the cold rinsing bath.

ii. Cold rinse

Rinsing of the five samples was conducted at the end of the dyeing process to remove dyes from the fiber and inter- 
fiber surfaces and to neutralize the alkaline medium.

iii. Oxidation and rinse

Oxidation was achieved for the sample of dye bath 5 , in open air for $15 \mathrm{~min}$ for the rinsing phases.

At the end of the dyeing process, two successive rinses were conducted in cold water, with the residual rinse bath $\mathrm{pH}$ being 7.2

\section{iv. Acidification}

The sample that was dyed in dye bath 4 was treated in acidic solution at $\mathrm{pH} 3.5 . \mathrm{CH}_{3} \mathrm{COOH}(0.1 \mathrm{ml})$ was added to $100 \mathrm{~mL}$ of solution.

\section{v. Drying}

The sample dyed in dye bath 4 was dried in a sterile environment at $60^{\circ} \mathrm{C}$ and $80^{\circ} \mathrm{C}$.

\section{vi. Hot rinse}

The five samples were treated in distilled water at $60^{\circ} \mathrm{C}$ over $15 \mathrm{~min}$ at $\mathrm{pH} 7$ with a liquor ratio of $1 / 100$. This rinse was used to delete the unfixed and weakly fixed dye inside the fibers.

\section{vii. Soaping}

Three samples were treated with $0.6 \mathrm{~g} / \mathrm{L}$ Marseille soap at $60^{\circ} \mathrm{C}$ for $15 \mathrm{~min}$, with a liquor ratio of $1 / 100$. The soaping step was used to test the washing fastness of the three samples that were dyed with the three dyeing processes: dye baths 2,4 and 5 .

\subsubsection{Spectral Analysis}

Spectrophotometer calibration
Spectrophotometer calibration was achieved by using a standard solution that was prepared according to the mass of wool yarn, the concentration of mordant tannin or alum added in dyebaths 2 and 3 and according to the $\mathrm{NaOH}$ and $\mathrm{CH}_{3} \mathrm{COOH}$ concentrations that were used in dye bath 4 . For the standard solution of dye bath 5, we added Argan's pulp and an alkaline solution according to the bath concentration.

To measure the soaping baths absorbances, standard solutions were prepared according to the concentration of Marseille soap used in each soaping bath.

Measurement of dye exhaustion and fixation rate

We removed $2 \mathrm{~mL}$ of solution from each dye bath for measurement. Each sample was diluted to $10 \mathrm{~mL}$ using the prepared standard solutions. The absorbance measurements are shown in Tables 1 and 2. The absorbances were measured at $500 \mathrm{~nm}$.

Measurement of soaping baths absorbances

We removed $2 \mathrm{~mL}$ of solution from each residual soaping bath for measurement. Each sample was diluted to $10 \mathrm{~mL}$ using the prepared standard solutions. The absorbance measurements are shown in Table 3. The absorbances were measured at $500 \mathrm{~nm}$.

\section{Results and Discussion}

\subsection{Exhaustion of Alizarin Dye}

The exhaustion rate measurements are presented in Table 1.

Table 1. Exhaustion rates of samples dyed in the five dye baths.

\begin{tabular}{llll}
\hline & Absorbance of intitial dye bath (Absi) & Absorbance of final dye bath (Absf) & Exhaustion dye rate ((Absi-Absf)/Absi)*100 \\
\hline Dye bath 1 & 0.291 & 0.197 & $32.3 \%$ \\
Dye bath 2 & 0.256 & 0.106 & $59.0 \%$ \\
Dye bath 3 & 0.341 & 0.136 & $60.1 \%$ \\
Dye bath 4 & 0.072 & 0.047 & $35.0 \%$ \\
Dye bath 5 & 0.165 & 0.065 & $61.0 \%$ \\
\hline
\end{tabular}

The maximum absorbance was achieved in the alkaline process using the reducer in dye bath 5 (the vat system), followed by the mordant dyeing process using alum (dye bath 3) or tannin (dye bath 2). The exhaustion rate of the fiber dyed by the alkaline process without reducer (dye bath 4) was relatively weak. This behavior can be explained by the high-pH medium ( $\mathrm{pH} 10)$ that increased the alizarine dye solubility and decreased its substantivity toward the fiber. The sample without mordant (dye bath 1) was absorbed weakly because of the low substantivity of the dyes that were extracted from the $R$. tinctorum plant.

\subsection{Fixation of Alizarin Dye}

Dyes that were removed during the cold rinse were relatively weak in the dyeing process, therefore, they were not taken into account in the calculation of the fixation dye rate. Measurements of the fixed and non-fixed dye rates are presented in Table 2.

Table 2. Fixation rates of samples dyed in the five dye baths.

\begin{tabular}{llll}
\hline & Absorbance of hot rinsing bath (Absr) & Fixation dye rate ((Absi-Absf-Absr)/Absi)*100 & No fixed dye rate (Absr/Absi)*100 \\
\hline Dye bath 1 & 0.075 & $6.5 \%$ & $26.0 \%$ \\
Dye bath 2 & 0.060 & $35.1 \%$ & $23.4 \%$ \\
Dye bath 3 & 0.095 & $32.2 \%$ & $28.0 \%$ \\
Dye bath 4 & 0.000 & $35.0 \%$ & $0.0 \%$ \\
Dye bath 5 & 0.014 & $52.1 \%$ & $8.5 \%$ \\
\hline
\end{tabular}


Different from previous results, a maximum fixation rate was achieved during the alkaline dyeing process using a reducer (dye bath 5) from the alkaline dyeing process using acidification treatment (dye bath 4 ) and by the mordant dyeing process using tannin (dye bath 2 ).

The higher fixation in dye bath 5 is attributed to good diffusion inside the fiber of the dye reducer form and because of the realization of more important physico-chemical interactions (hydrogen bonds) and physical interactions (Van der Waals interactions) with the fiber [13].

A lower ratio of unfixed dye or a higher dye fastness was achieved in dye bath 4. Therefore, completely exhausted dye was fixed on the fiber. Acidification converts the dye to no soluble molecules inside the fiber. Moreover, the dye establishes different bonds (hydrogen and Van der Waals) with different amino acids of the wool fiber. These yield an important washing and rubbing fastness to the dyed fiber.

The tannin mordant provides an increased fastness to the dyed fiber over the alum. This can be explained by the higher substantivity of tannin towards the fiber, because of the effect of a high tannin-molecule mass (especially gallic acid).

The dyed fiber without mordant had a lower dye-fixation rate and washing fastness. This may result from the low substantivity of the dyes that were extracted from $R$. tinctorum towards the fiber. These dyes formed hydrogen bonds and Van der Waals interactions, which ensure an increased stability and fastness of coloration.

\subsection{Washing Fastness}

The measurements obtained for the three soaping samples are presented in Table 3.

Table 3. The removed dye rates obtained for the three dyeing process.

\begin{tabular}{lll}
\hline & $\begin{array}{l}\text { Absorbance of Soaping } \\
\text { bath (Abss) }\end{array}$ & $\begin{array}{l}\text { Removed dye rate } \\
\text { ((Abss)/Absi)*100 }\end{array}$ \\
\hline Dye bath 2 & 0.041 & $16.0 \%$ \\
Dye bath 4 & 0.011 & $15.3 \%$ \\
Dye bath 5 & 0.035 & $21.2 \%$ \\
\hline
\end{tabular}

The values from these experiments confirm the conclusions described previously.

A higher washing fastness was achieved in dye bath 4 , followed by the mordant dyeing process in dye bath 2 . The dye that was removed in the washing step depends on the dyeing process. In fact, the acidification treatment step that converts dye into a non-soluble molecule inside the fiber provides increased fastness properties in the dyeing process compared with that with a reducer (dye bath 5). The good fastness that is observed when dyeing with tannin in dye bath 2 results from the different bonds (hydrogen and Van der Waals) that are established between the amino acid of the wool fiber and the tannin molecules and between these last and the dye molecules.

\section{Conclusion}

This study confirms the advantage of using an alkaline dyeing process with Argan's pulp reducer (in the vat system) to achieve a high degree of dye exhaustion and fixation followed by a dyeing process using tannin. During the alkaline dyeing process without a reducer, the $\mathrm{pH}$ alkaline medium was higher and the alizarine dye solubility had to be higher. Because of this solubility, the affinity to wool fiber decreases.

The study confirms the advantage of the alkaline dyeing process with acidification post treatment to achieve a high degree of washing fastness compared with the mordant dyeing process, and even with the alkaline dyeing process using reducer.

Dyeing using the tannin mordant achieved a higher degree of fixation and washing fastness than the alum mordant. This can result from the different bonds (hydrogen and Van der Waals) that were established by the tannin molecules with different amino acids of the wool fiber and the dye molecules.

\section{References}

[1] H. Bôhmer H., Natural Dyes and Textiles (Koekboya) Ed. Weppert, Schweinfurt (2002), 116-117.

[2] M. Marquet, Guide des teintures naturelles (plantes à fleurs), Ed. Belin (2011), 158-159.

[3] E. Dument, Teindre avec les plantes, Ed. Ulmer (2010), 100103.

[4] C. H. Goverdina. Derksen, Thesis "Analysis and isolation of anthraquinones from madder roots (Rubia tinctorum)", ISBN 90-5808-462-0, 12 october (2001), 17-18.

[5] D. De Santis, M. Moresi, «Production of alizarin extracts from Rubia tinctorum and assessment of their dyeing properties», Industrial Crops and Products, 26, 2, (2007), 151-162.

[6] C. H. Goverdina. Derksen, Thesis "Analysis and isolation of anthraquinones from madder roots (Rubia tinctorum)", ISBN 90-5808-462-0, 12 october (2001), 89.

[7] H. Itokawa, K. Mihara, K. Takeya, "Studies on a novel anthraquinone and its glycosides isolated from Rubia cordifolia and R. akane", Chem. Pharm. Bull, 31, 1983, 2353-2358.

[8] T. Masawaki., M. Taya, S. Tone, "Selective solvent extraction of ruberythric acid from madder roots and subsequent hydrolysis with 3-glucosidase", J. Ferment. Bioeng., 81 (1996), 567-569.

[9] Y. Chemchame, A. Errabhi, A. Makhloufi. Optimization of the Dyeing Conditions for Wool Fiber with Natural Indigo Using the Argan's Pulp. American Journal of Chemistry and Application, 2, No. 5, (2015), 70 - 74.

[10] J. Bellakhdar, La Pharmacopée marocaine traditionnelle: Médecine arabe ancienne et savoirs populaires, Paris, Ibis Press, 1997. 
[11] Z. K. Fellat, S. Smoughen, and R. Maurin, «Etude de la pulpe $\mathrm{du}$ fruit de l'arganier (argania spinosa) du Maroc. Matières grasse et latex» Actes Inst. Agron. Vet. (1987), 7.

[12] M. Faez M. «Modélisation de la répartition du transfert des métaux lourds et des oligoéléments dans les sols forestiers, l'huile d'argan et dans les différentes parties d'arganier»,
Thèse d'état, Fac. Sci. Unv. Mohamed V Agdal-Rabat-Maroc, (2012).

[13] Younes Chemchame, Mohamed El Moudden, Anass Mansar, Dyeing Wool Fiber with Natural Alizarin in a Vat System, American Journal of Applied Chemistry. 4, No. 5, (2016), 170-173. doi: 10.11648/j.ajac.20160405.12. 